University of Nebraska - Lincoln

DigitalCommons@University of Nebraska - Lincoln

Faculty Publications, Department of Psychology

Psychology, Department of

August 1996

\title{
The Course of Aggression in First-Grade Children with and without Comorbid Anxious Symptoms
}

Nick lalongo

John Hopkins University

Gail Edelsohn

Jefferson Medical College, Philadelphia, Pennsylvania

Lisa Werthamer-Larsson

Johns Hopkins University

Lisa J. Crockett

University of Nebraska-Lincoln, ecrockett1@unl.edu

Sheppard Kellam

Johns Hopkins University

Follow this and additional works at: https://digitalcommons.unl.edu/psychfacpub

Part of the Psychiatry and Psychology Commons

lalongo, Nick; Edelsohn, Gail; Werthamer-Larsson, Lisa; Crockett, Lisa J.; and Kellam, Sheppard, "The Course of Aggression in First-Grade Children with and without Comorbid Anxious Symptoms" (1996). Faculty Publications, Department of Psychology. 247.

https://digitalcommons.unl.edu/psychfacpub/247

This Article is brought to you for free and open access by the Psychology, Department of at DigitalCommons@University of Nebraska - Lincoln. It has been accepted for inclusion in Faculty Publications, Department of Psychology by an authorized administrator of DigitalCommons@University of Nebraska - Lincoln. 


\title{
The Course of Aggression in First-Grade Children with and Without Comorbid Anxious Symptoms
}

\author{
Nick Ialongo, ${ }^{1,4}$ Gail Edelsohn, ${ }^{2}$ Lisa Werthamer-Larsson, ${ }^{1}$ \\ Lisa Crockett, ${ }^{3}$ and Sheppard Kellam ${ }^{1}$
}

\begin{abstract}
We studied the course of aggressive behavior in an epidemiologically defined sample of first graders with and without comorbid anxious symptoms. Our primary purpose in doing so was to understand whether the stability of aggression in young children was attenuated or strengthened in the presence of comorbid anxiety. Previous studies of older children and adolescents had produced equivocal findings in this regard. Data on anxious symptoms were obtained through an interview of the children, whereas aggressive behavior was assessed through the use of a teacher interview and peer nominations. Assessments were performed in the fall and spring of first grade. In contrast to children classified as aggressive alone in the fall of first grade, boys and girls classified as aggressive and anxious in the fall of first grade were significantly more likely to be classified as aggressive in the spring in terms of teacher ratings and/ or peer nominations of aggression. Thus our findings suggest that the link between early and later aggression may be strengthened in the presence of comorbid anxious symptoms, rather than attenuated. Future studies are needed to identify the mechanisms by which the course of aggression is influenced by the presence of comorbid anxiety.
\end{abstract}

Submitted in final form June 6, 1994.

The writing of this paper was supported by the following National Institute of Mental Health grants: Epidemiologic Prevention Center for Early Risk Behavior (P50 MH38725); Periodic Outcome of Two Preventive Trials (1RO1 MH42968). The authors would like to thank the Baltimore Public City School System and the children and parents who participated in this study.

${ }^{1}$ Department of Mental Hygiene, School of Hygiene and Public Health, John Hopkins University, Baltimore, Maryland 21205.

${ }^{2}$ Division of Child and Adolescent Psychiatry, Jefferson Medical College, Philadelphia, Pennsylvania 19107.

${ }^{3}$ Department of Individual and Family Studies, Pennsylvania State University, University Park, Pennsylvania 16802.

${ }^{4}$ Correspondence: Dr. Nick Ialongo, Department of Mental Hygiene, School of Hygiene and Public Health, Johns Hopkins University, 624 North Broadway, Baltimore, Maryland 21205. 
The prevention and treatment of serious conduct problems in adolescence is

of paramount concern to mental health professionals and the public alike (National Institute of Mental Health, 1991). Considerable effort is now being expended on the prevention of antisocial behavior through intervention early in the life course, particularly in the early elementary school years (National Institute of Mental Health, 1991). The focus on the early elementary school years is consistent with evidence linking aggressive behavior in first grade with delinquency and violent behavior in adolescence (e.g., Kellam, Brown, Rubin, \& Ensminger, 1983; Kohlberg, Ricks, \& Snarey, 1984). Prevention and treatment resources are limited, however, and, as such, it is important to identify child and environmental characteristics that might differentiate among children whose aggressive behavior remits over time from those whose aggression endures. While the prediction from the early elementary school years to adolescence is strong, it is not perfect. Consequently, our limited resources need to be carefully targeted at those children at most risk for enduring aggression and antisocial behavior.

A handful of studies have pointed to a link between anxiety and the course or later manifestation of aggression in children and adolescents. For example, longitudinal studies by Graham and Rutter (1973) as well as others (Kohlberg et al., 1984; Mitchell \& Rosa, 1981) suggest that children with emotional disorders in the absence of conduct disorders are less likely to develop later delinquency than the general population. More recently, utilizing a sample of 177 school-aged boys, referred to one of three university-based outpatient clinics, Walker et al. (1991) found that boys diagnosed with conduct disorder (CD) and a comorbid anxiety disorder were markedly less impaired than boys with $\mathrm{CD}$ alone in terms of peer nominations for aggression ("fight most" and "meanest"), and of conflict with social systems (number of police contacts and school suspensions). Finally, Quay and Love (1977) report that juvenile delinquents who exhibited greater anxiety on a behavioral rating scale had lower rates of recidivism than nonanxious delinquents. Importantly, however. Quay and Love (1977) found a self-report measure of anxiety-withdrawal received a greater weight in predicting recidivism.

There are a number of possible explanations for the influence of co-morbid anxiety on the course and later manifestation of aggression in children and adolescents. For instance. Walker et al. (1991) contended that the effect of anxiety on aggression can be understood in terms of Gray's two-factor model of antisocial behavior. Gray (1987) proposed that normal and abnormal variations in personality are a product of the relative balance of two separate neurological systems of behavioral activation (BAS) and inhibition (BIS). According to Gray, enduring aggressive behavior is a function of excessive appetitive driving by the BAS and insufficient inhibition of antisocial behavior by the BIS However, in the anxious aggressive child the BIS may ultimately achieve balance with the BAS and lead to a reduction in aggressive behavior and/or its associated impairments. An alternative explanation, though not mutually ex- clusive, is that anxious aggressive children may be more highly developed in the social cognitive realm than solely aggressive children. They may be better at perceiving and reasoning about the consequences of their behaviors for themselves as well as for others (Dodge, 1986), and thus may be more likely to refrain from aggressive behavior in the future. Also in line with the social cognitive perspective, anxious aggressive children may have a more highly developed moral belief system (Kohlberg, 1978), which constrains them from committing future acts of aggression.

The studies by Graham and Rutter (1973) and others (Kohlberg et al., 1984; Mitchell \& Rosa, 1981; Walker et al., 1991) cited above suggest that the course and/or the later incidence of aggressive behavior in children and adolescents may be attenuated in the presence of comorbid anxiety. If this proves to be the case, it would have important implications for the more precise allocation of the limited preventive and treatment resources available for aggressive children. Ideally, the available resources should be targeted at those children who are at greater risk for enduring aggression and later violent behavior. Yet more comprehensive study of the link between the course of aggression and comorbid anxiety is in order given the relative dearth of studies in this area, as well some evidence that appears to conflict with the findings of studies cited above (Graham \& Rutter, 1973; Kohlberg et al., 1984; Mitchell \& Rosa, 1981). With regard to the latter, the findings of Kashani, Deuser, and Reid (1991) as well as Ialongo, Edelsohn, Werthamer-Larsson, Crockett, and Kellam (1994) suggest that anxiety and aggression may be positively related. For example, Kashani et al. found significantly more anxiety in both their "high-verbal" and high physical aggression subjects, whereas Ialongo et al. (1994) found a positive relationship between anxiety in the fall of first grade and aggression in the spring of first grade. Kashani et al., in explaining their findings, argued that some children will exhibit more aggressive behavior as a result of the anxiety that they are experiencing. Kashani et al. likened this behavior to the violent acts of paranoid individuals which arise from perceived fears of threat or hurt by others. In line with Kashani et al.. Dodge (1986) proposed a social information processing theory of aggression in children that suggests that at least some aggressive children exhibit a bias toward interpreting ambiguous social behavior on the part of peers as hostile or threatening and act accordingly by aggressing against the children they perceive to be threats. Of note, this formulation is also consistent with Gray's (1987) theory described above. That is, Gray included in his framework a third brain system - "the fight/flight system"- - which controls defensive aggression. In this third system, comorbid anxiety may serve to precipitate defensive aggression as the individual perceives threat or hurt by another and seeks to defend himself or herself by striking preemptively. Relatedly, the intensity of the individual's response in such a fight/flight situation may be even greater when both the BAS and BIS systems are activated in that one of the outputs of both the BAS and BIS is increased arousal. 
In light of the somewhat conflicting findings in the extant literature, there is an important need for longitudinal studies of the influence of comorbid anxiety on the course of aggression in children. The present study represents a first step toward a better understanding of the course of aggression in young children with and without comorbid anxious symptoms. We present data on the link between anxiety and the course of aggression from the first year of a longitudinal study of an epidemiologically defined population of first graders. Using data gathered in the fall and spring of first grade, we studied the question of whether the stability of aggression in children is attenuated or strengthened in the presence of comorbid anxiety.

\section{METHOD}

Subjects

Participants were 684 first-grade children from 19 public elementary schools in the eastern catchment area of the city of Baltimore, Maryland. The schools were selected from each of five sociodemographically distinct areas in eastern Baltimore. The children were originally recruited for participation in two school-based, preventive intervention trials targeting early learning and aggression. Given that our primary interest in this paper is to describe the natural or untreated course of anxious symptoms in school-aged children, only the 684 control subjects are included in the analyses described below. The exclusive use of the control subjects allows us to generalize our results to similarly defined, untreated community populations.

The five geographic areas in which the participating schools are located were defined by census tract data and vital statistics from the Baltimore City Planning Office. These areas vary by ethnicity, type of housing, family structure, income, unemployment, violent crime, suicide, and school drop out rates. With regard to the gender, ethnicity, and age of the subject population, $49.1 \%$ were male, $65.6 \%$ African-American, 31.6\% white, $0.3 \%$ Asian, $1.0 \%$ Native American, and $0.3 \%$ Hispanic, and for $1.2 \%$ of the children, ethnicity was either missing or refused. At first grade, the average age of the children was 6.6 years $(S D \pm 0.48)$. Of the 684 children available for participation in Fall of first grade, written parental consent was obtained for 570 children, or $83.3 \%$ of the population. Parents or guardians of thirty-four or $5.0 \%$ of the children refused to allow their children to participate, whereas those for 17 or $2.5 \%$ of the children gave verbal consent. Eight or $1 \%$ of the children had transferred out of the participating schools prior to consent being requested, whereas parents or guardians for 55 or $8 \%$ of the children failed to respond to the consent request.

Assessment Design and Measures

The design of the preventive trial from which these data were drawn included child assessments in the fall and spring of first grade. The fall of first grade assessments were carried out prior to the initiation of the interventions. The data gathered in these assessments included children's self-reports of anxious symptoms and peer nominations and teacher ratings of aggressive behavior. The data were obtained from teachers and children within the same $2 \frac{1}{2}$-hour period. Our decision to obtain both teacher and peers' reports of aggression was based on the fact that, whereas peers and teachers may overlap to a considerable extent in their assessments of aggressive behavior in the peer group, they are not always in total agreement. The lack of agreement is not necessarily a function of one rater being more accurate than another, but a product of the different social contexts that teachers and peers are operating within and, consequently, the different vantage points they have in observing and interpreting behavior in the peer group.

Revised Children's Manifest Anxiety Scale (R-CMAS). The R-CMAS (Reynolds \& Richmond, 1985) is a 37-item, self-report instrument designed to assess the level and nature of anxiety in children and adolescents from 6 to 19 years old. The child responds to each statement by marking a Yes or No answer. A response of Yes indicates that the item is descriptive of the child's feelings or actions, whereas a response of $\mathrm{No}$ indicates that the item is generally not descriptive. The Yes responses are counted to determine a Total Anxiety score. The R-CMAS has demonstrated good internal consistency and there is evidence supporting construct validity (Reynolds and Richmond, 1985). For the Total Anxiety score, the median reliability estimate was .82 (range .79 to .85). Stability coefficients for the Total Anxiety score ranged from .98 for a 3-week interval to .68 for a 9-month interval (Reynolds \& Richmond, 1985).

Teacher Observation of Classroom Adaptation-Revised (TOCA-R; Werthamer-Larsson, Kellam, \& Wheeler, 1991). The TOC-R is a structured interview with the teacher, administered by a trained assessor who follows a script precisely and responds in a standardized way to issues the teacher initiates. The interviewer records the teacher's ratings of individual children as the interview proceeds. Teachers respond to 36 items pertaining to each child's adaptation to classroom task demands Over the last 3 weeks. Adaptation is rated by teachers on a 6-point frequency scale $(1=$ almost never to 6 =almost always $)$ and covers three factor analytically derived dimensions: concentration problems, authority-acceptance/aggression, and shy behavior/social participation. Only the scores from the TOCA-R Aggression scale were used in the present study. The Aggression scale is made up of 7 items. Examples of the items include "breaks rules," "harms property," "harms others," and "starts fights." Werthamer-Larsson et al. reported test-retest correlations over a 4-month interval with different interviewers of .60 and a coefficient alpha of .92 for the Aggression scale.

The Peer Assessment Instrument (PAI). The PAI is a modified version of the Revised Pupil Evaluation Inventory (R-PEI; Pekarik, Prinz, Leibert, Weintraub, \& Neale, 1976). Ten items were selected from the R-PEI for use in the PAI. In some cases, items were shortened and reworded in order to be more 
readily comprehended by beginning first graders. The construct of interest in the present study was aggression. The items used to assess aggression included "mean to others," "fights," and "gets into trouble a lot." In terms of administration, a descriptor is read aloud to the class and the children are then instructed to circle the picture(s) of those children who fit the descriptor. Raw scores on each of the above dimensions are converted to standard scores based on the distribution of nominations within a child's classroom.

\section{Missing Data}

Six-hundred eighty-four control children were available for assessment in the fall of first grade and self-reports of anxiety were obtained from 570 (83.33\%) of these children. Of the 114 children from whom we failed to obtain self-reports of anxiety, there were 34 cases where parents refused to allow their child to participate, 57 cases where parents failed to respond to the consent request in sufficient time to allow for their child to be assessed, and 23 cases where the child was absent from school or otherwise unavailable during the scheduled assessment dates. There were no differences between these 114 children and the 570 children with anxiety data in terms of gender, age, or geographic area.

In the spring of first grade, we were able to locate $531(77.63 \%)$ of the 684 children available in the fall of first grade. Of these 531 children, we were able to obtain self-reports of anxiety from 415 children, or $60.67 \%$ of the original denominator of 684 children and $72.8 \%$ of those children from whom we obtained an anxiety score in the fall of first grade. We contrasted those children with anxiety scores at both points in time with those with a missing data point in terms of the following baseline characteristics: self-reports of anxiety and peer nominations and teacher ratings of aggressive behavior. No differences were found in terms of baseline anxiety or aggression.

\section{RESULTS}

\section{Analytic Plan}

The following steps were taken to examine the relationship between comorbid anxious symptoms and the course of aggression over the first-grade year. First, children were classified in the fall as either anxious and/or aggressive based on a quartile split of fall R-CMAS scores and teacher and peer ratings of aggression. Our use of the upper quartile is consistent with our previous work which suggested that, relative to children below the upper quartile, children in the upper quartile of anxiety were significantly more socially impaired (Ialongo et al., 1994). This also held true for the teacher ratings and peer nominations of aggression, with children in the upper quartile of aggression significantly more likely to be placed in special education classrooms and to have been suspended and/or expelled from school.
As pointed out above, children were classified in the fall as either anxious and/or aggressive based on a quartile split of fall R-CMAS scores and teacher and peer ratings of aggression. The upper quartile served as the outpoint for identifying a child as anxious and/or aggressive. Two samples were formed for the purpose of the analyses, one based on the distribution of teacher ratings of aggression and the other on the distribution of peer nominations of aggression. The peer data analyses provided us with an opportunity to determine the robustness of any effects found with the teacher data, using a different assessment method (peer nominations) and rater (i.e., peers).

Logistic regression analyses were carried out to examine the relationship between comorbid anxious symptoms and the course of aggression over the first-grade year. Spring aggression served as the dependent variable in each of the logistic regression analyses. The spring aggression variable was dichotomized, with the upper quartile of aggression serving as the cutoff point for identifying a child as aggressive. Fall anxiety and aggression served as the independent variables and were dummy coded so that aggressive children without anxiety were contrasted with either aggressive or anxious children, anxious and aggressive children, or anxious children without aggression. The logistic regression analyses allowed us to determine to what extent the presence or absence of comorbid anxiety in the fall predicted spring aggression. The analyses were performed separately for boys and girls owing to considerable evidence of gender differences in aggressive behavior in children (Cohn, 1991).

In the teacher analyses, the spring teacher ratings of aggression served as the dependent variable and teacher ratings of aggression and child self-reports of anxiety in the fall were used as the independent variables. Similarly, in the peer analyses, spring peer nominations of aggression served as the dependent variable and peer nominations of aggression and child self-reports of anxiety in the fall were used as the independent variables. In each set of logistic regression analyses, spring anxiety was entered into the equation at the first step along with geographic area. In this way the effects of geographic area and spring anxiety on spring aggression were controlled for.

\section{Teacher Ratings}

Table I contains the results of the logistic regression analyses for males, whereas Table II contains the results for females. The odds ratio represents the change in the odds of the dependent variable associated with a one unit change in the independent variable. Once again the contrast group is aggressive children alone. A 95\% confidence interval was computed for the odds ratios. In terms of teacher ratings, we did find that the course of aggression over first grade was influenced by the presence of comorbid anxiety. However, rather than finding an attenuation in the relationship between fall and spring aggression in the pres- 
Table I. Strength of the Relationship (Relative Odds in Logistic Regression) for Males Between Comorbid Status in the Fall and Aggression in the Spring

\begin{tabular}{|c|c|c|c|c|}
\hline & \multicolumn{4}{|c|}{ Spring Aggression } \\
\hline & \multicolumn{2}{|c|}{ Teacher ratings ${ }^{a}$} & \multicolumn{2}{|c|}{ Peer nominations ${ }^{a}$} \\
\hline & OR & $95 \% \mathrm{CI}$ & OR & $95 \% \mathrm{CI}$ \\
\hline $\begin{array}{l}\text { Not aggressive or anxious vs. } \\
\text { aggressive alone }\end{array}$ & $16.49^{d}$ & 3.59 to 36.22 & $4.3^{c}$ & 1.82 to 8.50 \\
\hline $\begin{array}{l}\text { Aggressive }+ \text { anxious vs. ag- } \\
\text { gressive alone }\end{array}$ & $3.34^{b}$ & 1.01 to 15.01 & $4.73^{c}$ & 1.86 to 14.85 \\
\hline $\begin{array}{l}\text { Anxious alone vs. aggressive } \\
\text { alone }\end{array}$ & $9.92^{d}$ & 3.67 to 25.53 & $5.25^{b}$ & 1.29 to 13.87 \\
\hline
\end{tabular}

${ }^{a} \mathrm{OR}=$ odds ratio; $\mathrm{CI}=$ confidence interval.

${ }^{b} p<.05$.

$p<.01$

${ }_{p}<.001$.

Table II. Strength of the Relationship (Relative Odds in Logistic Regression) for Females Between Comorbid Status in the Fall and Aggression in the Spring

\begin{tabular}{llllll}
\hline & \multicolumn{4}{c}{ Spring aggression } \\
\cline { 2 - 3 } & \multicolumn{3}{c}{ Teacher ratings ${ }^{a}$} & & \multicolumn{2}{c}{ Peer nominations ${ }^{a}$} \\
\cline { 2 - 3 } \cline { 5 - 6 } & $\mathrm{OR}$ & $95 \% \mathrm{CI}$ & & $\mathrm{OR}$ & $95 \% \mathrm{CI}$ \\
\hline $\begin{array}{l}\text { Not aggressive or anxious vs. } \\
\quad \text { aggressive alone }\end{array}$ & $5.23^{c}$ & 1.80 to 10.91 & & 1.80 & 0 to 5.10 \\
$\begin{array}{c}\text { Aggressive + anxious vs. } \\
\text { aggressive alone }\end{array}$ & $5.40^{b}$ & 1.17 to 14.72 & & 1.98 & 0 to 12.93 \\
$\begin{array}{c}\text { Anxious alone vs. aggressive } \\
\text { alone }\end{array}$ & $4.30^{c}$ & 1.66 to 16.11 & & 1.03 & 0 to 3.21 \\
$\begin{array}{l}{ }^{a} \mathrm{OR}=\text { odds ratio; } \mathrm{CI}=\text { confidence index. } \\
b_{p}<.05 .\end{array}$ \\
$c_{p}<.01$.
\end{tabular}

ence of comorbid anxiety, we found a strengthening of that relationship. This was true for both boys and girls. More specifically, in contrast to boys classified as aggressive alone in the fall of first grade, aggressive and anxious boys were about three times more likely to be in the top quartile of teacher-rated aggression in the spring of first grade. Similarly, aggressive and anxious girls in the fall of first grade were about five times more likely than aggressive-alone girls to be in the top quartile of teacher-rated aggression in the spring. In terms of the contrast between anxious-alone and aggressive-alone children, both boys and girls classified as anxious alone were significantly less likely to be in the top quartile of teacher-rated aggression in the spring. More specifically, anxiousalone boys were nearly 10 times less likely and anxious-alone girls about four times less likely than their aggressive-alone counterparts to be in the top quartile of teacher-rated aggression in the spring.

\section{Peer Nominations}

For boys the peer nomination results were similar to those stemming from the teacher ratings. This was not the case for girls, however. In contrast to boys classified as aggressive alone in the fall, aggressive and anxious boys in the fall of first grade were nearly five times more likely to be in the top quartile of peer nominations of aggression in the spring. For girls, the contrast between the aggressive-alone and aggressive and anxious groups was not significant. In terms of the contrast between anxious-alone and aggressive-alone children, boys classified as anxious alone, but not girls, were significantly less likely to be in the top quartile of peer-nominated aggression in the spring. More specifically, anxious-alone boys were about five times less likely than aggressive-alone boys to be in the top quartile of peer-nominated aggression in the spring.

\section{DISCUSSION}

The primary purpose of the present study was to determine whether the course of aggression in first grade would be attenuated or strengthened in the presence of comorbid anxious symptoms. Consistent with Kashani et al. (1991) and Ialongo et al. (1994), we found a strengthening of the relationship between fall and spring aggression in the presence of comorbid anxiety. More specifically, in contrast to children classified as aggressive alone in the fall of first grade, children classified as aggressive and anxious were significantly more likely to be in the top quartile of spring aggression. This finding held for both boys and girls in terms of teacher ratings, but only for boys in terms of peer nominations.

The fact that we did not find an effect for girls based on the peer nominations is difficult to explain, particularly given that we found such an effect in terms of teacher ratings. In line with Coie, Dodge, and Kupersmidt (1990), whereas peers and teachers may overlap to a considerable extent in their assessment of aggressive behavior in the peer group, they are not always in total agreement. The lack of agreement is not necessarily a function of one rater being more accurate than another, but a product of the different social contexts that teachers and peers are operating within and, consequently, the different vantage points they have in observing and interpreting behavior in the peer group. The forces in the peer group operating to maintain aggression appear to vary by gender (Patterson, Reid, \& Dishion, 1992) and our findings may reflect those differences.

Consistent with the "fight/flight" formulation offered in the introduction, which was based on an integration of Gray's (1987) biobehavioral theory of per sonality and the work of Kashani et al. (1991) and Dodge (1986), one possible explanation for the increased stability of aggression in anxious aggressive children may be an enduring perception of their environment's as hostile and potentially harmful; as such, the third brain system within Gray's framework the 
fight/flight system - may be regularly activated in these children. Accordingly, anxious aggressive children may be primed to react aggressively at the slight est provocation, which, in turn, may elicit aggression or other aversive consequences from peers and other socializing agents such as parents and teachers. These negative reactions from peers, teachers, and parents may reinforce the anxious aggressive child's perception of the environment as hostile and threatening, thereby perpetuating his or her aggressive stance. On the other hand, the factors eliciting aggressive behavior in the aggressive-alone child may be less stable - for example, the disruption of effective parenting practices associated with a parental illness, a marital separation or divorce, or a loss of a job (Patterson et al., 1992).

Of note, our finding that anxious-alone children, particularly boys, were significantly less likely to manifest later aggressive behavior than aggressivealone children is generally consistent with the longitudinal studies by Graham and Rutter (1973) as well as others (Kohlberg et al., 1984; Mitchell \& Rosa, 1981), which suggested children with emotional disorders in the absence of conduct disorders are less likely to develop later delinquency than the general population. Thus, anxiety in the absence of aggression may serve as a protective factor. That still leaves the question as to why our findings and those of Walker et al. were discrepant (1991). Of course, the Walker et al. study was cross-sectional in nature, but, nevertheless, one might hypothesize that if CD children with comorbid anxiety are less impaired than CD children without comorbid anxiety, the former may have a better long-term prognosis. One possible explanation for the discrepancy centers around the differences in sampling procedures and that there are at least two subgroups of anxious children. One of these subgroups may be concerned with fears of social evaluation and the second with physical harm (Campbell \& Rapee, 1994), where the fight/flight system in Gray's (1987) framework is highly active. Perhaps, whereas our unselected, community sample was dominated by anxious aggressive children who feared physical harm, the Walker et al. clinic sample was largely made up of anxious children whose primary fears centered on the social evaluation of others. Thus, they may gave been more likely to conform to social mores. A second, although not unrelated explanation, centers around the notion, offered by both Gray and Dodge (1986), of two different forms of aggression-predatory or proactive and defensive or reactive aggression. In accord with Gray's theory, comorbid anxiety may be more likely to have a dampening effect on predatory or proactive aggression than on defensive aggression, where the fight/flight system is activated. Once again the Walker et al. outpatient clinic sample might have been dominated by proactive aggressives, whereas our unselected, community population may have featured more defensive aggressives. Clearly, further study of mechanisms by which comorbid anxiety may influence the course of aggressive behavior is in order. Such studies will need to clarify the nature of the aggression examined, that is, predatory or defensive. However, to make this distinction validly and reliably, one may have to utilize an experimental manipulation, such as the one used by Murphy, Pelham, and Lang (1992), as opposed to the rating scales used here. This is particularly important for those aggressive children, described by Dodge, who tend to interpret ambiguous cues as hostile and who engage in defensive aggression once their fight/flight systems are activated. On a rating scale, the aggression these children exhibit may be assessed as predatory in that the rater, whether it be a teacher, parent, or peer, may be insensitive to the "ambiguous" cues and thus conclude the aggression was not provoked.

The present study was not without limitations. First, given the short-term longitudinal design we cannot be assured that aggressive anxious children will have a worse long-term outcome than aggressive-alone children. We are currently following this population of first graders as they move into middle school, and we will be in a position to answer the question of whether the anxious aggressive children do have worse outcomes. Second, our measures of anxiety and depression represent first-stage or screening measures. A comprehensive psychiatric assessment including multiple measures, methods, and informants would likely have allowed a more precise determination of the presence of disorderlevel behavior and symptoms. Finally, the measures used to assess aggression in this study did not allow us to confidently subdivide our aggressive children into proactive and reactive subgroups.

In conclusion the results of the present study suggest that comorbid anxiety may play a pivotal role in the course of aggression in young children. Further longitudinal research into this issue is clearly needed given the dearth of long-term longitudinal studies addressing this issue. Additional research of this kind is also necessary given the importance of identifying comorbid features early in the life course of aggressive children that will allow for the targeting of our scarce preventive intervention resources more precisely and economically. Finally, further study of the mechanisms by which anxiety and other comorbid characteristics might come to moderate the course of aggression in children is also warranted. If we can understand the natural mechanisms which explain the remission of aggression, we may be able to develop preventive interventions that reflect that knowledge.

\section{REFERENCES}

Campbell, M., \& Rapee, R. (1994). The nature of feared outcome representations in children. Journal of Abnormal Child Psychology, 22, 99-112.

Cohn, L. D. (1991). Sex differences in the course of personality development. Psychological Bulletin, 109, 252-266.

Coie, J., Dodge, K., \& Kupersmidt, J. (1990). Peer group behavior and peer social status. In S. R. Asher \& J. D. Coie (Eds.), Peer rejection in childhood (pp. 17-59). Cambridge, UK: Cambridge University Press. 
Dodge, K. A. (1986). A social information processing model of social competence in children. In M. Perlmutter (Ed.), Minnesota Symposium on Child Psychology. Hillsdale, NJ: Erlbaum.

Graham, P., \& Rutter, M. (1973). Psychiatric disorders in the young adolescent: A follow-up study. Proceedings of the Royal Society of Medicine, 66, 1226-1229.

Gray, J. A. (1987). The psychology of fear and stress (2nd ed.). Cambridge, U.K.: Cambridge University Press.

Ialongo, N., Edelsohn, G., Werthamer-Larsson, L., \& Kellam, S. (1994). The significance of selfreported anxious symptoms in first grade children. Journal of Abnormal Child Psychology, 22, 441-456.

Kashani, J., Deuser, W., \& Reid, J. C. (1991). Aggression and anxiety: A new look at an old notion. Journal of the American Academy of Child and Adolescent Psychiatry, 30, 187-191.

Kellam, S., Brown, C. H., Rubin, B. R., \& Ensminger, M. E. (1983). Paths leading to teenage psychiatric symptoms and substance use: Developmental epidemiological studies in Woodlawn. In S. B. Guze, F. J. Earls, \& J. E. Barrett (Eds.) Childhood psychopathology and development (pp. 17-51). New York: Raven Press.

Kohlberg, L. (1978). The cognitive developmental approach to behavior disorders: A study of the development of moral reasoning in delinquents. In G. Serban (Ed.), Cognitive deficits in the development of mental illness. New York: Bruner/Mazel.

Kohlberg, L., Ricks, D., \& Snarey, J. (1984). Childhood development as a predictor of adaptation in adulthood. Genetic Psychology Monographs, 110, 91-172.

Mitchell, S., \& Rosa, P. (1981). Boyhood behavior problems as precursors of criminality: A fifteen year followup study. Journal of Child Psychology and Psychiatry, 22, 19-33.

Murphy, D., Pelham, W., \& Lang, A. R. (1992). Aggression in boys with attention deficit hyperactivity disorder: Methylphenidate effects of naturalistically observed aggression, response to provocation, and social information processing. Journal of Abnormal Child Psychology, 20, 451-466.

National Institute of Mental Health. (1991). Implementation of the national plan for research on child and adolescent mental disorders (Program Announcement PA-91-46). Washington, DC: U.S. Government Printing Office.

Patterson, G. R., Reid J., \& Dishion, T. (1992). Antisocial boys. Eugene, OR: Castalia.

Pekarik, E., Prinz, R., Leibert, C., Weintraub, S., \& Neale, J. (1976). The pupil evaluation inventory: A sociometric technique for assessing children's social behavior. Journal of Abnormal Child Psychology, 4, 83-97.

Quay, H., \& Love, C. (1977). The effect of a juvenile diversion program on rearrests. Criminal Justice and Behavior, 4, 377-396. Reynolds, C. R., \& Richmond, B. O. (1985).

Revised Children's Manifest Anxiety Scale (R-CMAS) manual. Los Angeles: Western Psychological Services.

Walker, J., Lahey, B., Russo, M., Frick, P., Christ, M., McBurnett, K., Loeber, R., StouthamerLoeber, M., \& Green, S. (1991), Anxiety, inhibition, and conduct disorder in children: I. Relations to social impairment. Journal of the American Academy of Child and Adolescent Psychiatry, 30, 187-191.

Werthamer-Larsson, L., Kellam, S., \& Wheeler, L. (1991). Effect of first grade classroom environment on shy behavior, aggressive behavior, and concentration problems. American Journal of Community Psychology, 19, 585-602. 